\title{
GOSTO E DELEITE: CONSTRUÇÃO E SENTIDO DE UM MENU ELEGANTE
}

\author{
Taste and delight: construction and meaning \\ of an elegant menu
}

\author{
Maria Cecília Barreto Amorim Pilla*
}

\begin{abstract}
RESUMO
Partindo do pressuposto de que o alimento consumido tende a transferir analogicamente ao comensal algumas de suas características, o presente estudo quer articular o conceito de gosto às estratégias da obtenção do prestígio e da distinção social levando em conta a escolha dos cardápios, pois a comida que vai à boca não é neutra. A composição do menu e a futura partilha das iguarias por ele elencadas pode constituir-se em instrumento da construção da identidade e da natureza daqueles que as consomem. É necessário, para isso, reconhecer, no consumo dos alimentos, fatores culturais, sociais e psicológicos capazes de influenciar nas preferências alimentares.

Palavras-chave: gosto, distinção social, prestígio.
\end{abstract}

\section{ABSTRACT}

Starting of the presupposed that the consumed food tends to transfer analogically to the commensal some of its characteristics, the present study wants to articulate the concept of taste to the strategies of the attainment of prestige and the social distinction, taking in account the choice of the menus, therefore, the food that goes to the mouth is not neutral. The composition of the menu and the future allotment of the dainty for it listed can consist in instrument of the construction of the identity and the nature of that they ingest them.

Key-words: taste, social distinction, prestige.

* Professora Doutora da PUC-PR. 
O presente artigo faz parte de um estudo maior, no qual desenvolvi uma análise sobre as mudanças e permanências dos preceitos considerados como "adequados" perante os alimentos, utilizando como fontes manuais de civilidade, de administração do lar e livros de cozinha que circulavam no Brasil desde os primeiros anos do século XX até a década de 1960. Não se trata, no entanto, apenas de uma análise da evolução das maneiras à mesa em geral, mas do que as regras contidas nesses manuais recomendavam, de forma implícita ou explícita, em relação a elementos de cultura e poder capazes de constituir a diferenciação, distinção ou a integração social.

Nesse sentido, as relações entre os alimentos e as categorias sociais podem ser vislumbradas nos gostos diferenciados ou nas atitudes diante dos alimentos. O consumo alimentar não acontece somente pela necessidade biológica, mas obedece a um sistema simbólico complexo que envolve acepções sociais, históricas, sexuais, econômicas, religiosas, éticas e estéticas ligadas à cultura e ao poder. Conforme Henrique Carneiro, "A fome biológica distingue-se dos apetites, expressões dos variáveis desejos humanos e cuja satisfação não obedece apenas ao curto trajeto que vai do prato à boca, mas se materializa em hábitos, costume, rituais, etiqueta". ${ }^{1}$

Da mesma forma, Igor Garine prevê que, no campo fisiológico, as pessoas são levadas por um impulso instintivo a se alimentar. Como animais, os seres humanos sentem fome. Mas os ingredientes que ingerem devem, além de satisfazer-lhes as necessidades biológicas, cumprir certas características ligadas às escolhas, principalmente determinadas pelo gosto e pelo cheiro. Essas escolhas trazem consigo a marca cultural do meio na qual se desenvolveram. Alimentar-se, portanto, transcende o ato de "matar" a fome, pois há a necessidade da satisfação dos apetites, ou seja, o desejo de "voltar a experimentar a sensação de bem-estar consecutivo ao consumo alimentar. É aqui que se situam os fundamentos da arte de bem comer". ${ }^{2}$

Conforme Carlos Roberto Antunes dos Santos, ao longo da história, a cozinha e os prazeres à mesa construíram-se como importantes componentes da ciência do saber viver. Nesse sentido é que "comportamentos, representações, valores e mensagens, relações de alteridade" ${ }^{3}$ devem ser levados em conta

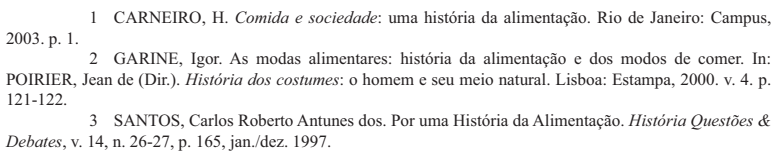

3 SANTOS, Carlos Roberto Antunes dos. Por uma História da Alimentação. História Questões \& Debates, v. 14, n. 26-27, p. 165, jan./dez. 1997. 
na análise sobre a ingestão dos alimentos, pois o consumo do alimento em companhia de outras pessoas certamente revela-se como expressão de sociabilidade e de poder.

O gosto alimentar é portador de laços sociais. Os fatores culturais, sociais e psicológicos atuam na formação e transmissão do sabor. A promoção do gosto alimentar está intimamente ligado a uma forte verbalização. O prato, a cozinha, os instrumentos, os alimentos e as bebidas são objetos de discursos, de discussões, de debates, de preferências e de exclusões.

Ter gosto é estar de posse das condições de apreender sensorialmente os alimentos, como também de verbalizar e compartilhar as sensações que daí provém. Sensações estas que foram as mesmas do passado e que se crê que sejam as mesmas do futuro. ${ }^{4}$

Para Fischler, ${ }^{5}$ basicamente três fatores influenciam em nossas escolhas alimentares, classificando os alimentos em "comíveis" e "incomíveis". Segundo o autor, disponibilidade e custo pesam ao optar-se por esta ou aquela comida. O sabor, a necessidade e a força do corpo também devem ser levados em conta e encontram, inclusive, comprovação científica, sendo possível afirmar que certos sabores constituem uma preferência inata, como o doce, por exemplo; outros, uma aversão inata, como o amargo. Quanto ao hábito, é certo que a familiaridade aumenta a aceitabilidade. Por outro lado, todas essas considerações não são suficientes para explicar uma questão tão complexa como a alimentação e o gosto.

Reconhecendo, portanto, que os fatores culturais, sociais e psicológicos influenciam nas escolhas alimentares, é possível empreender a análise a que se propõe este artigo, o qual, sob o ponto de vista da escolha dos cardápios e das modas alimentares, procura destacar as questões de cultura e poder relacionadas ao gosto diferenciado e diferenciador.

4 SANTOS, op. cit., p. 169 1995. p. $60-65$.

5 FISCHLER, Claude. El (h)omnivoro: el gusto, la cocina y el cuerpo. Barcelona: Anagrama, 


\section{Nomeando sabores e selecionando iguarias}

$\mathrm{O}$ ato de alimentar-se reúne componentes do homem biológico e do homem social. Biologicamente, o homem é uma criatura onívora, ou seja, tem a liberdade de alimentar-se tanto de vegetais como de animais. Por outro lado, influem em suas escolhas, além das necessidades biológicas, elementos de caráter simbólico, cultural e social.

Nas suas mais diversas significações, "gosto" relaciona-se à alimentação, tanto no que diz respeito aos sabores propriamente ditos quanto no que se refere às escolhas alimentares, levando-se em conta a qualidade simbólica que representam.

O tema alimentação, relacionado ao conceito de gosto, deve ser encarado em sua complexidade, ou seja, é preciso reconhecer que os alimentos revestemse em suas funções sociais, culturais e biológicas. Assim sendo, o ato de ingerir determinados alimentos deve ser compreendido à luz do real e do imaginário.

Uma das possibilidades para a compreensão das questões que envolvem "gosto" e alimentos é justamente o "princípio da incorporação" proposto por Fischler ao analisar "as funções da culinária". Para ele, o ato de alimentarse se dá tanto no plano real como no imaginário, o resultado disso é ingerir um alimento com todas as suas propriedades, tornando-o, com isso, parte do que nos constituímos. Nesse sentido, "chegamos a ser o que comemos". ${ }^{6}$

Nesse ponto, é possível estabelecer relações com o processo civilizador, pois, da mesma forma que civilizamos as maneiras, e em especial as maneiras à mesa, podemos também "civilizar" nossos gostos ou, pelo menos, "aprender" a nos posicionar diante da ingestão de determinados alimentos ou até mesmo saber oferecer, preparar ou prepará-los de forma "diferenciada e diferenciadora". Mesmo que sobre o gosto não atuem somente elementos racionais, no sentido de que "gosto" de determinados pratos porque são "chics" ou porque pessoas de status costumam servi-los, até porque, mesmo sob essa análise, percebemos o quanto o gosto é influenciado pelo imaginário. Nesse sentido, Fischler afirma: "O alimento absorvido nos modifica desde o interior". O alimento é capaz de influenciar a construção da identidade, da natureza daquele que o ingere. Mesmo nas sociedades contemporâneas, ainda há a crença de que o alimento consumido tende a transferir analogicamente ao comensal algumas de suas características.?

Assim é que a organização do cardápio torna-se uma das questões mais complexas e "trabalhosas", mais ainda quando há convidados a receber, pois

6 FISCHLER, op. cit., p. 66.

7 Id. 
quando preparamos uma iguaria são muitos os fatores a considerar, mesmo porque jamais podemos deixar de lado uma questão: os alimentos a serem servidos apresentam gosto bom ou ruim a meus convidados ou a minha família. Pensando nisso, os manuais, em geral, indicam sempre uma razoável variedade em relação à composição dos cardápios, mesmo aqueles indicados para o diaa-dia familiar. Marta de Betânia, em suas Noções de economia doméstica, na década de 1950, chama atenção desse fato dizendo que: "A composição do cardápio requer especial cuidado da dona da casa ou da pessoa responsável pela organização do banquete". 8

No mesmo período, Gilda Helena posiciona-se da mesma forma ao advertir, em seu Aprenda a ser esposa e mãe, que: "Tem a dona de casa, na alimentação que ela prepara, um elemento que tanto poderá proporcionar saúde e felicidade aos membros da família, como acarretar-lhes, de um modo insidioso, as mais diversas moléstias de nutrição". E, movida por uma preocupação substancial, acrescenta: "A pessoa encarregada de preparar as refeições deve saber ainda que não é apenas a quantidade dos alimentos que deve ser considerada, mas também a sua qualidade". 9 Da mesma forma, observamos igual preocupação no início do século XX, em O lar doméstico, quando Cleser indicava que: "Na composição do cardápio deve-se tomar mais em consideração a qualidade das iguarias do que a quantidade". ${ }^{10}$

8 BETÂNIA, Marta de. Noções de economia doméstica. São Paulo: Saraiva, 1957. p. 195. Trata-se de um livro completo no que diz respeito à higiene, economia, moral e cultura, munido de uma interpretação cristã de estilo acessível e "sobriedade de savoir vivre". O livro é escrito em forma de perguntas e respostas, a partir das quais valores e padrões de conduta são transmitidos, versando, em suas dez partes, sobre assuntos que interessam a todos e que vão desde a definição de economia doméstica, passando por regras concernentes à arrumação da casa em geral, regras de civilidade, até a correspondência e o jogo, entre outros assuntos.

9 HELENA, Gilda (pseudônimo de Albertina Guimarães). Aprenda a ser esposa e mãe: um guia prático e seguro para as donas de casa. Rio de Janeiro: Irmãos Pongetti, 1955. p. 53. A natureza e a finalidade dessa obra é dar conselhos à mulher sobre como bem dirigir seu lar a partir de sugestões sobre organização, arrumação e ordenamento das atividades domésticas.

10 CLESER, Vera. $O$ lar doméstico: conselhos para boa direcção de uma casa. Rio de Janeiro: Laemmert \& C., 1906. p. 214. Esse manual de administração do lar traz, de forma didática, uma série de informações sobre a administração da casa. A obra é dividida em quatro partes. Na primeira, a autora contempla ensinamentos sobre a organização do que ela chama de "movimento diário" do lar. A segunda trata das partes da casa - salas, quartos, cozinha, despensa, utensílios de cozinha, o quintal e o jardim. Na terceira, a que aqui mais interessa, particularmente, fala da preparação do banquete, o jantar íntimo, trazendo algumas indicações sobre a "disposição das iguarias" e a arte de educar a criada. A quarta e última parte refere-se ao que se chama de "occupações especiaes", que consistiriam em: a arte de comprar; normas referentes à limpeza de copos, pratos, xícaras, panelas; e ainda sobre a "chimica domestica", mais destinada à limpeza de talheres, móveis, tapetes, vidros e espelhos, entre outros, trazendo também recomendações, receitas especiais para lavagem e limpeza de objetos ou roupas. Típico manual de serviço doméstico, é completo no que diz respeito a tornar a dona de casa capaz para lidar com as complexas situações do cotidiano do lar, ao mesmo tempo em que dá à mulher traquejo para o desenvolvimento de suas habilidades sociais. 
Refletindo sobre os conselhos de Betânia e Gilda Helena, observamos o quanto é complexa a questão da alimentação, pois, em cada um deles, emerge mais e mais o que disse um dia Lévi-Strauss, que a comida não deve ser somente "boa de comer", mas também "boa de pensar".

E pensando não só sobre a comida, mas também em como ela é importante como elemento de distinção social, Íside Bonini, em seu Boas maneiras: em sociedade, da década de 1960, lembra: "A dona de casa perfeita revela-se, de modo especial, ao receber visitas. De seus conhecimentos e pericia depende muito o conceito que se formulará acêrca da sua educação e bom gôsto, do seu requinte e finura. Por conseguinte, é imprescindível que ela esteja familiarizada com os múltiplos detalhes da etiquêta social, condição necessária para assegurar completo êxito". ${ }^{11}$ A etiqueta, nesse caso, fica claramente identificada como elemento excludente ou de inclusão ou mesmo mecanismo de diferenciação, de destaque.

Em seus ensinamentos sobre "boas maneiras", Bonini considera bastante importante o desempenho da dona de casa no papel de anfitriã. Aponta que, ao escolher a composição do cardápio, ato de extrema responsabilidade, e a forma de serviço, não podemos deixar de lado "as regras impostas pelas convenções; regras essas que constituem verdadeiros cânones e adotadas por todos os povos civilizados, ciosos de sua cultura". ${ }^{12}$

Explicitamente, Bonini relaciona as questões alimentares, envolvendo aí principalmente a composição do cardápio e tudo o que compreende as boas maneiras à mesa, ao conceito de civilização e cultura. Assim, ao ser capaz de receber perfeitamente seus convidados, os anfitriões não estarão somente dando provas de sua preparação social, mas também demonstrando pertencer ao grupo "civilizado" no sentido de "culturalmente" favorecido, pois a autora também considera que: "A refeição servida numa mesa não constitui apenas uma questão alimentar, embora a boa alimentação seja um elemento imprescindível; o que realmente importa é conseguir a perfeita harmonia entre os comensais e, de acôrdo com a ocasião, harmonizar os pratos que se servem". ${ }^{13}$

Resultado da "civilização", a boa mesa é um espaço em que se partilham sabores, idéias, culturas. "Cozinha do olhar", considerada "bela arte"

11 BONINI, Íside. Boas maneiras: em sociedade. São Paulo: Edigraf, 1963. p. 75. Por considerar seu "Boas maneiras" uma necessidade, Íside recomenda a todos instruírem-se convenientemente sobre o que chama "a arte de ser bem educado", pois, segundo ela, "saber exatamente o que temos que fazer é sumamente importante. (...) Saber e fazer bem feito o que se tem a fazer constitui a ciência do êxito, do triunfo, do desembaraço natural que distingue a pessoas".

12 Ibid., p. 75.

13 Ibid., p. 76. 
por Perpétua de Lemos, a culinária não somente se dirige, segundo ela, a todos os nossos sentidos, mas também é capaz de refiná-los. "Um prato que nos agrada influi sôbre a vista, o olfato, o paladar e até sôbre o nosso psiquismo". Como "fonte de educação para o nosso intelecto e de refinamento para os nossos sentidos", Perpétua não acredita ser o domínio da arte culinária um talento nato, mas muito mais resultado do cultivo dos espíritos, não restrito, portanto, às pessoas mais abastadas. ${ }^{14}$

Ao citar o livro Essai de Gastronomie, de Édouard de Pomiane, Perpétua considera a gastronomia inserida num processo civilizador ao dizer que ela "evolui diàriamente com a civilização. Quanto mais os sentidos se refinam, mais as emoções produzidas pelos alimentos se multiplicam e mais o espírito humano procura aumentar o número de receitas culinárias", ${ }^{15}$ constituindo-se em exercício inventivo e inovador. Fruto da civilização, continua Perpétua, a arte culinária se liga às nações "ultracivilizadas", pois "as cozinhas que se impõem na Europa são a da França e a da Itália, justamente os dois países que têm sido os principais focos da civilização e cultura ocidentais". Capaz de introduzir um padrão de civilização, a cozinha francesa é fundamental na construção de um mundo "civilizado", modelo de "harmonia, de equilíbrio e beleza". ${ }^{16}$

Não está, portanto, necessariamente, nem no luxo ostensivo nem no requinte das receitas a garantia do sucesso de uma refeição, mas muito mais no preparo esmerado, na criatividade e na experiência daquele que a oferece e/ou a prepara. Segundo Rosa Maria, "com inteligencia e habilidade, a dona da casa pode suprimir diversos requintes de luxo, sem que se note. Principalmente se ela fôr amavel e simples. Um sorriso, uma palavra bôa, faz esquecer muitas falhas". ${ }^{17}$ Afinal, como bem diz Tavares de Miranda:

14 LEMOS, Perpétua. Enciclopédia de arte culinária. Rio de Janeiro: Globo, 1954. v. 1, p. 3. A autora distribuiu os assuntos abordados nessa enciclopédia em dois volumes. O primeiro volume divide-se em duas partes: "Mesa e cozinha", que traz esclarecimentos sobre organização da cozinha, técnicas culinárias, segredos culinários, temperos, planejamento de cardápios, serviço de mesa e a arte de trinchar; e "Bebidas em geral", que trata de assuntos como vinhos, refrescos, licores e outras bebidas. No segundo volume, a autora traz a parte referente ao receituário.

15 Ibid., p. 3

16 Id.

17 ROSA MARIA. A arte de comer bem. Rio de Janeiro: Officina Industrial Graphica, 1933. p. 15. Um livro de receitas que traz, em sua apresentação, algumas instruções para a preparação de jantares e a colocação à mesa. Encaminhando-se de forma particular à sua filha, que lhe pede socorro por ter convidados para o jantar, Rosa Maria, na verdade, dirige-se a todas as donas de casa. Dividido em doze partes, $A$ arte de comer bem é completo tanto no que diz respeito a menus para almoços e jantares de cerimônia como para almoços e jantares mais íntimos. 
...não importa muito que os pratos tenham nomes exóticos ou sejam indicados em francês: o importante, mesmo, nos casos em que se deseja dar uma nota de distinção, é que o serviço seja agradável e que as iguarias estejam apetitosas. O mais é acessório. ${ }^{18}$

Além do imaginário, o princípio da incorporação, segundo Fischler, também se relaciona à medicina. "O alimento é o primeiro e, sem dúvida, o principal meio de intervenção sobre o corpo, antes do medicamento, como o traduz a fórmula hipocrática, 'De teus alimentos farás a medicina". ${ }^{19}$ Mais uma vez, a incorporação do alimento se relaciona ao conceito de diferenciação social, no sentido de que podemos afirmar que "me transformo no que como, e a maneira como me alimento faz-me distinto".

Isso pode ser observado no primeiro e no último preceito do "Decálogo da boa alimentação do Dr. Hélion Póvoa”, trazido por Gilda Helena em seu guia para as donas de casa da década de 1950:

I-Quem come mal, vive pior, morre cedo, cria filhos débeis, trabalha menos e adoece mais. (...) X - Sendo a vida alimento transformado em energia é sobre a mesa que se decidem, verdadeiramente, os destinos não só dos povos mas da humanidade. Banir da mesa a higiene é condenar o povo ao enfraquecimento. ${ }^{20}$

Nessas duas cláusulas, em especial, percebemos a relação estabelecida entre ensinamentos médico-nutricionais e princípios gastronômicos, pois a autora, citando o médico, mune-se de preceitos científicos para demonstrar o cuidado a ser dispensado à preparação dos alimentos.

Nesse sentido, podemos relacionar a esses conselhos nutricionais as questões sobre a "qualidade" dos alimentos a serem ingeridos. Em 1906, Vera Cleser, em $O$ lar doméstico, advertia sobre o cuidado na preparação de uma boa refeição. Para ela,

18 MIRANDA, José Tavares de. Boas maneiras: e outras maneiras. São Paulo: Bestseller, 1965. p. 66. O autor desse manual de civilidade apresenta-o como uma verdadeira fonte de aprendizagem sobre o convívio social. Trata de temas como: normas de convivência; comportamento pessoal; regras à mesa; recepções; bebidas; visitas; convites; correspondência; casamento; vida em família; moda; e luto.

19 Ibid., p. 67.

20 HELENA, op. cit., p. 74-75. 
...entre os innumeros gozos materiaes que a sagacidade humana soube inventar, occupa o primeiro logar uma bôa refeição. Uma comida saborosa tem desde os tempos da mais remota antiguidade uma poderosa influencia sobre os homens.

Portanto, "cozinhar bem exige principalmente reflexão e grande pontualidade em todas as manipulações necessarias. Com cuidado e séria bôa vontade póde-se adquirir esta habilidade". ${ }^{21}$

Outro ponto importante a ser analisado acerca da função da incorporação do alimento defendido por Fischler é a questão da partilha alimentar, ou seja, a idéia de que ser convidado a partilhar o alimento com determinados grupos pode se configurar no significado de pertencer àquele grupo ou pelo menos numa oportunidade de vir a pertencer, relacionando-se dessa forma à integração social. Segundo Fischler: "A incorporação é igualmente fundadora da identidade coletiva e, ao mesmo tempo, da alteridade. A alimentação e a cozinha são um elemento capital do sentimento coletivo de pertencimento". ${ }^{22}$ Portanto, o alimento que vai à boca não é neutro.

No interior de uma mesma cultura, um grupo se define muito freqüentemente por pertencer ou não a outro grupo pelo que come. "Na Índia a estrutura hierárquica da sociedade se traduz claramente através dos alimentos que cada casta pode ou não consumir". Da mesma forma, Fischler completa que:

\footnotetext{
Não se trata somente do que o comensal incorpora das propriedades da comida; simetricamente, pode dizer-se que a absorção de uma comida incorpora o comensal a um sistema culinário e, portanto, a um grupo que o pratica, a menos que se o exclua irremediavelmente. ${ }^{23}$
}

Assim, a exclusão também está presente no sentimento de pertencimento, pois posso passar a pertencer a um determinado grupo ou, se já pertenço, devo manter esse papel, pois posso ser excluído. “...cada incorporação implica também uma oportunidade e uma esperança: tornar-se mais do que se é ou que se deseja ser. O alimento constrói o comensal: é natural, portanto, que o comensal busque construir-se comendo". ${ }^{24}$

21 CLESER, op. cit., p. 237-238.

22 Ibid., p. 68.

23 Id.

24 Ibid., p. 69. 
Se o "homem é aquilo que come", o que gosta de comer representa seu caráter, portanto, se gosta de alimentos refinados, seu gosto lhe confere qualidade e distinção.

Desde meados do século XVII, o significado de "gosto" deixou de ser exclusivamente ligado ao paladar, campo da alimentação. Nos dicionários franceses do final do século XVII, seu significado é bem mais extenso no sentido figurado.

Mas a noção de "homem de gosto" só se desenvolveu bem mais tarde, não tão tarde que não possa estar relacionada a esse contexto. $\mathrm{O}$ "Dictionnaire de l'Accadémie a registra apenas em 1932, mas Voltaire já a utilizava em 1764 em seu Dicionário filosófico". "O gourmet sente e reconhece prontamente a mistura de dois licores; o homem de gosto, o connaisseur verá num rápido relance a mistura de dois estilos; verá o defeito ao lado do ornamento". Este conceito interessa mais à função do gosto no jogo social..$^{25}$

No século XVII, a aristocracia se viu ameaçada pelos parvenus. Eles travavam lutas no plano político para conservar o seu poder. Essa rivalidade se travou também no plano simbólico do fausto. "Em tais circunstâncias o bom gosto não seria a arma forjada pela aristocracia para conservar um pouco de sua preeminência simbólica?”. ${ }^{26}$

Assim como na literatura do século XVII, os livros de culinária aristocráticos atacavam e zombavam da burguesia da época. L'art de bien traiter denunciava as práticas e os gostos da burguesia e das classes inferiores. No século XVII, a grande culinária seguiu novas orientações, renovando-se, mas não desistiu de "diferenciar-se das cozinhas populares e burguesas". ${ }^{27}$

Segundo Flandrin: "A mecânica da distinção social e as rivalidades de classes no interior das elites parecem contribuir para a elaboração da noção de gosto e a ideologia do progresso das artes. No entanto, não poderiam explicar tudo", pois "Nem todo homem de gosto saiu das velhas famílias aristocráticas e nem todos os aristocratas de velha cepa primavam pelo bom gosto". ${ }^{28}$

E completa: "Não é evidente que a noção de gosto tenha surgido de uma crítica ao fausto dos novos ricos". Mas não há como negar que o gosto pertencia a um pequeno número de indivíduos. La Bruyère fala disso. Por outro lado, vários autores achavam que o gosto era inato, como Saint-Évremond, por

25 FLANDRIN, Jean-Louis. A distinção pelo gosto. In: ARIES, Philippe; CHARTIER, Roger. História da vida privada: da Renascença ao Século das Luzes. São Paulo: Cia. das Letras, 1991. p. 300.

26 Ibid., p. 302.

27 Ibid., p. 302, 305

28 Ibid., p. 306 
exemplo, pois "nas reflexões sobre o gosto ninguém expressou a idéia de que pudesse ser hereditário e pertencer apenas a pessoas bem nascidas". ${ }^{29}$

No século XVII, tanto em relação aos salões literários franceses quanto às recepções marcadas pelo requinte à mesa, encontravam-se pessoas de origem plebéia. Nas décadas seguintes, seriam as afinidades de gostos e as maneiras requisitos indispensáveis para sentar-se à mesma mesa e não o berço, a fortuna ou a profissão.

Gostos em matéria de língua, literatura, música, pintura, arquitetura, jardinagem, mobiliário, vestimenta, cozinha, etc. Nestes campos diferentes, a função das artes não era apenas - nem talvez principalmente - tornar mais confortável ou prazerosa a vida das elites, e sim permitir-lhes manifestar seu bom gosto, novo critério de distinção social. ${ }^{30}$

O caráter de elite e não sua origem, aristocrática ou burguesa, vai abrir precedente para a conservação da expressão "bom gosto" para as sociedades democráticas, pois a boa mesa revela o gosto verdadeiro de foro íntimo.

Valor intrínseco ou extrínseco, inato ou adquirido, o fato é que, a partir do século XVII, mais e mais se discute sobre o caráter do "bom gosto". Muitos são os critérios e os âmbitos de distinção, político, militar ou econômico. O sucesso em qualquer deles não garante destaque no âmbito social. De acordo com Flandrin, "foi no âmbito da vida mundana que os critérios de distinção se multiplicavam ao longo dos séculos". A Idade Média inventou a cortesia, que se transformou em civilidade, urbanidade, polidez. "O século XVII inventou o bom gosto".

Essa noção que participa do ser e do ter, é a primeira de todas que acabamos de mencionar que se refere ao indivíduo como consumidor. Sem dúvida, isso tem alguma relação com o fato de que os grandes senhores, que a partir do século XVII definitivamente perderam a maioria de seus antigos poderes políticos e militares, passam a ser, sobretudo grandes consumidores; e também está ligado ao fato de que o campo do consumo e do luxo é aquele em que as diversas classes componentes das elites sociais nos séculos XVII e XVIII podem comunicar-se com maior facilidade. ${ }^{31}$

29 FLANDRIN, op. cit., p. 306

30 Ibid., p. 307-308.

31 Ibid., p. 308 
O "bom gosto", no entanto, não é encarado por todos como uma qualidade hereditária, pois em muitas "boas mesas" pessoas de diferentes origens compartilharam o requinte gastronômico. A partir do século XVIII, seriam as afinidades de gostos e maneiras os requisitos indispensáveis para estar à mesa, e não o berço, a fortuna ou a profissão. A partir de então, diz Antunes do Santos: ${ }^{32}$

\begin{abstract}
...haverá o rompimento com o modo tradicional de se alimentar, com a reestruturação dos gostos passando por novas categorias e fazendo com que o prazer gastronômico seja marcado por esta nova cozinha do olhar, atraído pelas cores dos alimentos, marcada pela delicadeza dos aromas e das ervas finas. Tais combinações elaboradas e servidas em diversas fases, trazem consigo também nova forma de servir, o servir francês, de forma vertical.
\end{abstract}

Nesse sentido, ainda se colocam muitos dos manuais analisados, dentre eles o de Perpétua de Lemos, na década de 1960, que considera:

\author{
Para um bom jantar \\ Há que se considerar \\ Três coisas amáveis \\ E indispensáveis: \\ Mesa atraente \\ Comida gostosa \\ Dona de casa \\ Meiga e graciosa... ${ }^{33}$
}

Vê-se que as qualidades em receber, oferecer e partilhar os alimentos consiste muito mais em qualidades de esmero, cuidado, do que no luxo das iguarias. Isso fica claro quando os manuais trazem dicas da composição dos cardápios, tal como o faz Carmem D'Ávila, quando alerta que: "Compor um cardápio requer cuidados, e não o devemos fazer ao acaso", pois o sucesso dos jantares consiste na "graça e na imaginação inerentes a uma dona de casa" em saber escolher as iguarias e servi-las com "esmerada elegancia". ${ }^{34}$

\footnotetext{
32 SANTOS, op cit, p. 165

33 LEMOS, op. cit., p. 266

34 D’ÁVILA, Carmem. Boas maneiras. Rio de Janeiro: Civilização Brasileira, 1946. p. 116-119. Escrito em 1946, já em sua sexta edição, esse manual de civilidade apresenta regras de cortesia em dez capítulos que versam sobre os seguintes temas: a cortesia fora de casa; cumprimentos; em sociedade; em vilegiatura; à mesa; a correspondência; a igreja; o nascimento; o casamento; e o testamento.
} 
Percebe-se que é muito mais a qualidade de "elite" e não sua origem aristocrática que vai abrir caminho para a conservação da expressão "bom gosto" nas sociedades democráticas. Com isso, a mesa revela muito mais o gosto verdadeiro de foro íntimo, do que a origem daqueles que a apreciam. $\mathrm{O}$ "bom gosto" torna-se então uma importante virtude social a ser reconhecida pelos outros e pelo próprio indivíduo que o possui.

A essa discussão liga-se a idéia de Fischler da dimensão social dos alimentos. Às funções sociais dos alimentos, segundo ele, somam-se funções imaginárias, ou seja, a composição do cardápio e a maneira de consumir certos alimentos, regras de boas maneiras, podem compor ícones de distinção social. Para Fischler, os alimentos são portadores de sentido, "o tomate e o caviar, de maneira muito diferente, nutrem ambos tanto o imaginário como o corpo". ${ }^{35}$ Produtos e marcas considerados de "elite" são capazes de distinguir simbolicamente seu consumidor, não somente em relação à oportunidade de aumento de renda, mas na maioria das vezes satisfaz ambições e reafirma sua identidade social.

Outro exemplo de alimento que carrega forte significado simbólico é a carne, seu consumo e partilha foram objeto de estudo de diversos estudiosos. $\mathrm{Na}$ sociedade medieval, a carne que provém da caça é considerada um alimento dos nobres. Sua forma de preparo se relaciona à categoria social de quem a ingere. Os camponeses comem a carne basicamente cozida, a nobreza prefere assados, as carnes grelhadas. Além dos gostos e predileções pessoais, diz Montanari, isso é resultado da "expressão de valores culturais precisos: segundo uma tradição bem determinada em antropologia, o uso do fogo sem a mediação da água e dos recipientes domésticos implica uma relação mais estreita com o cru e a natureza selvagem e, portanto, com a imagem profundamente 'animal' que a nobreza da Idade Média quer dar de si mesma". ${ }^{36}$

Segundo o mesmo autor, a ciência dietética medieval, embora ligada às tradições romanas, passou a valorizar o consumo da carne tanto no campo nutricional quanto no campo social. Em relação ao caráter nutricional, a carne é fonte de força, mas também é elemento que liga o caráter força ao elemento poder (este baseado na força física e militar para o comando); decorrendo daí a relação entre o consumo da carne e a cultura e o poder. A carne, portanto, constitui-se elemento de poder.

35 FISCHLER, op. cit., p. 80.

36 MONTANARI, M. Os camponeses, os guerreiros e os sacerdotes: imagem da sociedade e estilos de alimentação. In: FLANDRIN, Jean-Louis; MONTANARI, Massimo. (Orgs.). História da Alimentação. São Paulo: Estação Liberdade, 1998. p. 292. 
Na Baixa Idade Média, progressivamente, a carne vai desaparecendo das mesas dos camponeses, que se tornam consumidores de cereais, de legumes secos ou verdes. Na segunda metade do século XV, Montanari constatou, em seus estudos, dois fenômenos: o empobrecimento da alimentação camponesa e a diferenciação progressiva dos regimes alimentares de acordo com as classes sociais. Dessa forma, os privilégios alimentares ressaltam a tradição que havia consagrado a aristocracia como a classe dos comedores de carne e em cuja mesa se desprezam os legumes. E com a consolidação do processo de reurbanização européia estruturam-se, a partir de então, dois modelos diferentes de consumo alimentar, um rural, de subsistência, e outro urbano, de mercado. Nesse mesmo momento, há também a cristalização das boas maneiras, que aos poucos se consagram em meio à sociedade de corte, servindo para determinar culturalmente os domínios do privilégio, definindo-os tanto em seus conteúdos quanto em suas formas. As atitudes corteses ou urbanas se revelam, antes de tudo, como uma rejeição ao comportamento camponês.

Para Montanari, os modos de arrumar a mesa, as maneiras, as peças da baixela, assim como a arte gastronômica, que se refina nos últimos séculos da Idade Média, servem como sinais distintivos. As exigências do equilíbrio nutricional, a dietética e a gastronomia andam juntas. A cultura medieval, diz ele,

\footnotetext{
...dará a essas "exigências" orientações mais especificamente sociais, identificando-as não como atributos da pessoa (como preconizam os ensinamentos da dietética) e sim de classe. Os nobres terão sua dietética, sua gastronomia, suas maneiras de se portar à mesa. Os camponeses terão outras. A mesa e a alimentação se tornarão o principal instrumento para corroborar e manter a ordem estabelecida. ${ }^{37}$
}

A alimentação já era, nesse período, elemento de diferenciação social, acreditava-se que as pessoas das classes superiores consumiam pratos mais refinados. Para Grieco, os tratados culinários do século XVI são claros a esse respeito, "dirigidos à nobreza lembravam a seus leitores que a 'superioridade' da camada mais refinada da sociedade guardava uma certa relação com seu modo de alimentar-se". ${ }^{38}$

37 MONTANARI, M. Modelos alimentares e identidades culturais. In: FLANDRIN, Jean-Louis; MONTANARI, Massimo. (Orgs.). História da Alimentação. São Paulo: Estação Liberdade, 1998. p. 386.

38 GRIECO, A. F. Alimentação e classes sociais no fim da Idade Média e na Renascença. In FLANDRIN, Jean-Louis; MONTANARI, Massimo. (Orgs.). História da Alimentação. São Paulo: Estação Liberdade, 1998. p. 472 
Entre os séculos XV e XVIII, fatores caracterizadores do mundo moderno favoreceram o refinamento da gastronomia e das maneiras à mesa. A partir de então, o consumo das carnes e dos alimentos em geral passou a ter novos significados. Flandrin menciona, para esse período, o caso das carnes de açougue, que até então eram relativamente desprezadas e passaram a ter melhor aceitação pelas elites. Nota também a diminuição do consumo de pão, pratos de grãos e papas no regime das elites sociais e o aumento do consumo dos legumes, que haviam sido abandonados aos camponeses. ${ }^{39}$

No século XVII, o livro Il trinciante, do cozinheiro italiano Vicenzo Cervio, destaca os vários tipos de corte e apresentação das carnes. E o autor chama especial atenção à questão da apresentação das carnes: especialista que era na arte do corte, Cervio ensina como segurar a posta de carne ou pernil diante dos convivas e como parti-la, ressaltando o lugar de destaque que a sua partilha ocupava nas mesas européias do período.

A burguesia recém-saída da Revolução aspirava ao poder, à nostalgia e aos requintes da nobreza. Ao mesmo tempo em que a fome grassava na Europa na virada do século XVIII para o XIX, a mesa do burguês se refinava e se convertia em símbolo de poder e de prestígio. A partir de então, a arte gastronômica encontrou dias fastos. E nessa arte, a carne, seu preparo e sua partilha encontravam-se em voga. O consumo de determinados cortes e seu preparo representavam um papel relevante no cenário social. Maria José de Queiroz conta que, num dos jantares filosóficos (comuns em meados do século XIX na França), um ilustre freqüentador das grandes mesas francesas provou, em 1867, um "Chateaubriand": "cercado de batatas fritas, um filet com o dobro da grossura de um bife comum, nada sangrento, mas ao corte da faca o suco da carne correu dando origem a uma coisa viva e animada". ${ }^{40}$

Os alimentos - a carne, o caviar ou o tomate -, vistos sob esse enfoque, tornam-se, então, fonte de poder e de prestígio. A mesa refinada, a gastronomia requintada, o "bom gosto" e as "boas maneiras" que o acompanham tornam-se símbolos de distinção social acessíveis a todos que "possam bancá-los".

39 FLANDRIN, J.-L. Da cristandade ocidental à Europa dos Estados Unidos (séculos XV-XVIII). In: FLANDRIN, Jean-Louis; MONTANARI, Massimo. (Orgs.). História da Alimentação. São Paulo: Estação Liberdade, 1998. p. 545. 1988. p. 119.

40 QUEIROZ, M. J. de. A comida e a cozinha: ou iniciação à arte de comer. Rio de Janeiro: Forense, 


\section{Considerações finais}

$\mathrm{O}$ conjunto de regras referentes à organização de menus contidas nos manuais analisados constitui importante elemento de diferenciação e qualificação social. Influenciados pelas idéias de civilização e progresso em voga no período analisado, parecem ter contribuído para a construção de estilos e influenciado as preferências alimentares que se queriam distintivas. Junto ao refinamento das maneiras, do gosto pela arte culinária, a busca do luxo e a valorização do belo inspiraram a organização do cardápio e a arte de bem receber.

A análise das fontes permitiu refletir sobre as orientações a respeito da composição das refeições, vendo nelas concepções de poder e prestígio, de refinamento e requinte, revelados no bom gosto e no comportamento civil.

Os banquetes das sociedades ocidentais, desde há muito, contribuem para manifestar publicamente o lugar dos que neles participam. A ostentação está tanto no efeito visual como na qualidade dos alimentos oferecidos. Os modos de vestir, de falar, as habilidades à mesa, a postura, a composição e as opções de cardápio e as predileções alimentares podem classificar os indivíduos.

Qualidades do saber viver implementam-se a partir do saber fazer. E esse saber fazer reveste-se em valor distintivo quando as escolhas, de modo particular, traduzem-se em atos como destreza e percepção da arte da vivência social.

No reduzido espaço da mesa, é preciso construir qualidades, tanto no âmbito da seleção como no da preparação da comida. O bom senso revelado na escolha do menu, complementado pelo serviço esmerado, constrói modelos capazes de diferenciar e integrar os iguais.

\section{Referências}

BETÂNIA, Marta de. Noções de economia doméstica. São Paulo: Saraiva, 1957.

BONINI, Íside. Boas maneiras: em sociedade. São Paulo: Edigraf, 1963.

CARNEIRO, H. Comida e sociedade: uma história da alimentação. Rio de Janeiro: Campus, 2003. 
CLESER, Vera. O lar doméstico: conselhos para boa direcção de uma casa. Rio de Janeiro: Laemmert \& C., 1906.

D'ÁVILA, Carmem. Boas maneiras. Rio de Janeiro: Civilização Brasileira, 1946.

FISCHLER, Claude. El (h)omnivoro: el gusto, la cocina y el cuerpo. Barcelona: Anagrama, 1995.

FLANDRIN, Jean-Louis. A distinção pelo gosto. In: ARIES, Philippe; CHARTIER, Roger. História da vida privada: da Renascença ao Século das Luzes. São Paulo: Cia. das Letras, 1991.

FLANDRIN, Jean-Louis; MONTANARI, Massimo. (Orgs.). História da Alimentação. São Paulo: Estação Liberdade, 1998.

GARINE, Igor. As modas alimentares: história da alimentação e dos modos de comer. In: POIRIER, Jean de (Dir.). História dos costumes: o homem e seu meio natural. Lisboa: Estampa, 2000. v. 4.

HELENA, Gilda. Aprenda a ser esposa e mãe: um guia prático e seguro para as donas de casa. Rio de Janeiro: Irmãos Pongetti, 1955.

LEMOS, Perpétua. Enciclopédia de arte culinária. Rio de Janeiro: Globo, 1954. v. 1.

MIRANDA, José Tavares de. Boas maneiras: e outras maneiras. São Paulo: Bestseller, 1965.

QUEIROZ, M. J. de. A comida e a cozinha: ou iniciação à arte de comer. Rio de Janeiro: Forense, 1988.

ROSA MARIA. A arte de comer bem. Rio de Janeiro: Officina Industrial Graphica, 1933.

SANTOS, Carlos Roberto Antunes dos. Por uma História da Alimentação. História Questões \& Debates, v. 14, n. 26-27, p. 165, jan./dez. 1997. 